\title{
Child's Congenital Heart Diseases: A Follow-Up of 101 Cases at Charles De Gaulle Pediatric Teaching Hospital (CDG-PTH) of Ouagadougou
}

\author{
Georges Kinda',2, Koudougou Jonas Kologo',3, Aimé Bama2, Georges Rosario Christian Millogo ${ }^{1,3}$, \\ Salimata Traoré ${ }^{2}$ Lassina Dao1,2, Solange Ouédraogo Yougbaré ${ }^{1,2}$, Aïssata Kaboré1,2, Sonia Kaboret ${ }^{1,2}$, \\ Kisito Nagalo1,2, Laure Toguyéni Tamini1,2, Relwendé Aristide Yaméogo ${ }^{4}$, Fla Kouéta1,2, Diarra Yé1,2, \\ Léonie Claudine Lougué Sorgho ${ }^{1,5}$, Patrice Zabsonré1,3
}

\footnotetext{
${ }^{1}$ University Department of Medical Science (UFR/SDS)/University Ouaga1 Professor Joseph KI-ZERBO, Ouagadougou, Burkina Faso

${ }^{2}$ Medical Pediatric department of Charles De Gaulle Pediatric Teaching Hospital of Ouagadougou, Ouagadougou, Burkina Faso

${ }^{3}$ Cardiology Department of Yalgado Ouédraogo Teaching Hospital, Ouagadougou, Burkina Faso

${ }^{4}$ Medical Department of Regional Health Center in Koudougou, Koudougou, Burkina Faso

${ }^{5}$ Laboratory of medical imagery of Charles De Gaulle pediatric teaching Hospital of Ouagadougou, Ouagadougou, Burkina Faso

Email: georgeskinda@yahoo.fr
}

How to cite this paper: Kinda, G., Kologo, K.J., Bama, A., Millogo, G.R.C., Traoré, S., Dao, L., Yougbaré, S.O., Kaboré, A., Kaboret, S., Nagalo, K., Tamini, L.T., Yaméogo, R.A., Kouéta, F., Yé, D., Sorgho, L.C.L. and Zabsonré, P. (2016) Child's Congenital Heart Diseases: A Follow-Up of 101 Cases at Charles De Gaulle Pediatric Teaching Hospital (CDG-PTH) of Ouagadougou. Open Access Library Journal, 3: e3092.

http://dx.doi.org/10.4236/oalib.1103092

Received: September 24, 2016

Accepted: November 5, 2016

Published: November 9, 2016

Copyright $\odot 2016$ by authors and Open Access Library Inc.

This work is licensed under the Creative Commons Attribution International

License (CC BY 4.0).

http://creativecommons.org/licenses/by/4.0/

(c) (i) Open Access

\section{Abstract}

Introduction: The management of congenital heart diseases in countries with limited technical facilities poses real problems to practitioners. Yet, a good medical followup permits to improve these children's life quality before any eventual surgery. Our study aims at examining the evolutionary and prognostic aspects of these congenital heart diseases in order to understand their evolution in our context. Materials and Methods: Our work is a continuation of a prospective, transversal and descriptive survey concerning all the children with congenital heart diseases in hospitalization or in consultation led from January 1st 2012 to December 31st 2012 in the Charles De Gaulle Center Pediatric Teaching Hospital (CDG-PTH) in Ouagadougou. Results: In 2012, we kept under observation 101 cases of congenital heart diseases representing $69.18 \%$ of the 146 cases of heart diseases with an impact of $0.79 \%$ of the 12,838 patients who were admitted at CDG-PTH. The interventricular septal defect occupied the first place of all malformative heart diseases with $43.56 \%$ of cases. The average age of patients at the moment of the diagnosis was 17 months old with extremes ranging from two (2) days old to fifteen (15) years old. The sex-ratio was 1.06. Throughout the follow-up of the children until the end of the six months' survey, it was possible for us to meet again 52 patients, we had no longer been in touch with 22 patients and 27 were dead. At the moment of the diagnosis, surgical treatment was recommended for $63.37 \%$ of the patients (64 cases) and only $7.81 \%$ (5 cases) were 
operated. The complicated cases were: Eisenmenger syndrome (6 cases representing $5.94 \%)$. We recorded a rate of $26.73 \%$ of death. Conclusion: Congenital heart diseases are relatively common at CDG-PTH. The high rate of mortality noticed is due to the lack of heart surgery and catheterism units in our country.

\section{Subject Areas}

Cardiology

\section{Keywords}

Congenital Heart Diseases, Echocardiography, Therapeutic, Evolution, Prognosis

\section{Introduction}

Congenital heart diseases are cardiovascular malformations present at birth and caused by a failure of development during the life of the embryo [1]. The important progress in medicine permitted the improvement of the survival rate of children suffering from these malformations. The Doppler echography is the key test which makes possible the confirmation of the diagnosis which is pre-natal in western countries and still post-natal in most African countries [2]. Once diagnosed, congenital heart diseases pose to practitioners real problems of management in our context. In fact, the lack of curative treatment through cardiovascular surgery in our context limits their management to a medical follow-up with many complications. Yet, a good follow-up permits to improve the life quality of these children before any eventual surgery.

In order to know more about child's congenital heart diseases, a prospective survey has been initiated at CDG-PTH in 2012 in the framework of our work.

Our work, which is a continuation of this survey, aims at studying the progressive and prognostic aspects of these infections [3] in order to know more about their evolution in our context.

\section{Methodology}

Our target population was made up of hospitalized or consulted children aged between zero and fifteen years, who presented clinical signs of congenital heart disease and where Echocardiography Doppler permitted to confirm the diagnosis between January 1st and December 31st 2012 congenital heart diseases. All children are descended of an African black population. Each child was then observed for sixteen (16) months according to his/her inclusion date. So, patients included in January 2012 were observed until April 2013 and those integrated in December 2012 were observed until April 2014. The variables included for analysis were age, sex, Down syndrome, the comparison of the signs between the time of the diagnosis and some at the end of survey (respiratory distress, thoracic deformation, digital hippocratism, arythmia, electric hypertrophia, cardiomegalia, radiographic bronchopneumopathy), the intervening of complications 
(endocarditis, Eisenmenger, death). The collected data were type-written and analyzed thanks to softwares "Epi info version 3.5.1" and "SPSS 21". To compare the data we used the exact test of Fisher with statistical significations of proportion being inferior to 0.05. The graphs were made with excel. Oral consent was given by one the parents. The child was always consulted with his parent. Patient could refuse to participate to the study without influence in his follow up.

\section{Results}

\subsection{Epidemiological Aspects}

In 2012, we examined 146 cases of heart diseases out of a total of 12838 patients which represents a percentage of $1.14 \%$. Congenital heart diseases which were 101 represent $69.18 \%$ of all the cases with an incidence of $0.79 \%$.

Out of the 101 cases, fifty-two (52) were really surveyed for sixteen (16) months, twenty-two (22) lost touch with us and twenty-seven (27) died.

The average age of patients was seventeen (17) months with extremes ranging from two (2) days to fifteen (15) years. Infants were the most numerous with sixty-four (64) cases and a percentage of $63.37 \%$ followed by new born with twenty-six (26) cases representing a percentage of $25.74 \%$. The majority was boys with a sex ratio of 1.06 .

\subsection{Clinical Aspects}

Dyspnea was the most common discovery during the diagnosis of congenital heart diseases with sixty-seven (67) cases and a percentage of $66.34 \%$. At the last check-up, the heart breath was the clinical sign the most frequent encountered with twenty-five (25) cases out of fifty-two (52) patients and a percentage of $48.08 \%$ compared to forty -two cases $(80.77 \%)$ in 2012 .

Besides, the respiratory distress was observed in five (5) cases with $9.62 \%$ compared to thirty-six cases (69.23\%) in 2012. However, we had observed six (6) cases (11.54\%) of digital hippocratism compared to two (2) cases (3.85\%) in 2012 and the appearance of thoracic deformation with four (4) children. The congenital malformation related to the most congenital heart diseases was "Down syndrome" noticed in ten (10) cases representing $9.90 \%$ with an association of atrioventricular canal (6 cases). Out of the fifteen (15) cases of atrioventricular canal we noticed six (6) patients with Down's syndrome facies $(40 \%)$

\subsection{Therapeutic Aspects}

In 2012, electrocardiogram was carried out on thirty-six (36) patients and twenty-four (24) abnormalities were noticed with nine (9) cases of right ventricular hypertrophy.

At the last check-up, we carried out an electrocardiogram on sixteen (16) patients and we recorded one (1) case of bi-ventricular hypertrophy and one (1) case of isolated left ventricular hypertrophy and each represented a percentage of $1.92 \%$.

During the diagnosis, the front chest x-ray was carried out on thirty-three (33) patients and there were thirteen (13) cases of cardiomegaly representing $12.92 \%$. The 
other anomalies namely the modification of the cardiac sides and radiographic bronchopneumopathy were ten (10).

The x-ray carried out on twenty (20) patients during the last check-up permitted to isolate five (5) cases of cardiomegaly (9.52\%).

\subsection{Evolutionary and Prognostic Aspects}

The most common complication was Eisenmenger's syndrome which could be seen on six (6) patients (5.92\%) followed by endocarditis, encephalophyosis and arythmia.

Out of the fifty-two (52) patients who are still alive and who were surveyed up to the end, the situation of forty of them (76.92\%) was estimated to be good whereas it was supposed to be bad for the other twelve (23.08\%).

As for cases of atrioventricular canal and complex congenital heart diseases (interventricular septal defect, single auricle, single ventricle, "mitral Artesia “, double outlet right ventricle) the prognosis was generally bad

\section{Discussion}

In our survey, congenital heart diseases had a hospital impact of $0.79 \%$. This number is superior to those of Himmetoglu in Turkey [4] and Bassiliet and his collaborators in Egypt [5] who had respectively incidences of $0.03 \%$ and $0.1 \%$. Yet, Ouafae [6] in Morocco found a percentage of $4.41 \%$.

The important variation of the incidence rate of these malformations could be explained by the inclusion criteria and the age of the patient during the diagnosis. In fact, it is easy for some interventricular canal defect and atrial septal defect of small size to heal during the first years of life. The means used for the diagnosis, the size of the samples and the setting could also have an impact on the incidence.

As for congenital affections, congenital heart diseases can be discovered at different ages of life. During our survey, the average age of patients was seventeen (17) months old with extremes ranging from two (2) days old to fifteen (15) years old. Our result is close to Sawadogo's [7] in Burkina-Faso who found an average age of sixteen point seven four (16.74) months old. Yet, Chaabouni and his associates in Tunisia [8] and Abdullah in Saudi Arabia [9] reported respectively an average age of twelve (12) and ten (10) months old. Our discovery age was "precocious" compared to Mpenda and associates' [10] in Congo (6.3 years old with extremes of nine (9) months old to fifteen (15) years old) and Lahlou's [11] in Morocco (5.21years with extremes of seven (7) days to seventeen (17) years). As a whole, the average age during the diagnosis varies according to the methodology undertaken. However, the advanced age of patients at the diagnosis in our survey could be explained by the fact that consultations are done late. A complete and systematic clinical examination of any new-born would reduce this discovery deadline and would lead to a better management of these malformations as well as a reduction of their morbidity-mortality.

We noticed a male predominance with fifty-two (52) boys (51.49\%) compared to forty-nine (49) girls (48.51\%) representing a sex-ratio of 1.06.The same fact was noticed 
by Diop [12] in Senegal with 1.11. Hammani and his associates in Tunisia found a female predominance with a sex-ratio of 0.79 and Sawadogo [7] in Burkina-Faso noticed an equal repartition of the two sexes. This variation in the sex-ratio could underline the lack of relationship between the sex and the appearance of congenital heart diseases.

Different symptoms can motivate parents to send their children to hospital for consultation. In our series, Dyspnea was the most common discovered circumstance with 66.34\%. The same observation was made by Sawadogo [7] in Burkina-Faso with 94.5\%; Hammani and his collaborators [13] in Tunisia with $89 \%$ and Kinda in Senegal [14] with $72.34 \%$. These data could be justified by the fact that several congenital heart diseases mostly manifest through a dyspnea, whose appearance disturbs parents and motivates them to sent their children for consultation. Depending on its severity, dyspnea can make sucking difficult or even impossible for new-born and infants and also prevent children from playing.

The evolution of the sick persons kept under observation was assessed at the clinical and paraclinical level and in accordance with therapeutic data. At the end of the survey, the cardiac breath was the most common sign during the examination of the fifty-two (52) patients observed with $48.08 \%$ compared to $80.77 \%$ at the moment of the diagnosis. The same observation was made in previous survey. Thalboussouma in BurkinaFaso [15] found this sign with $39.53 \%$ of his patients; Kokou and his collaborators in Togo [16] with $67 \%$ of the cases and Hammami [13] with $77.6 \%$ of his patients. Some more important data were objectivized by Damarou and his collaborators [17] in Togo in $83.5 \%$ of the cases and in Senegal by Kinda [14] with $91.49 \%$.

These results could be explained by the fact that the cardiac breath is a quasi-existent sign in heart diseases [18]. Its presence at the clinical examination of a child necessitates some complementary examinations mainly the Doppler echocardiography for the search of its organic origin or not.

During the diagnosis of the fifty-two (52) patients in 2012, the respiratory distress was the most common clinical sign with $69.23 \%$ after the heart murmur which represented $80.77 \%$. Nadia and her collaborators in Pakistan [19] objectivized the respiratory distress in $80 \%$ of the cases. It represents the clinical sign of many cases of heart diseases and its resistance to oxygen therapy constitutes generally an element of etiologic direction.

We noticed a decrease in the frequency of the respiratory distress ranging from $69.23 \%$ at the moment the diagnosis in 2012 to $9.62 \%$ at the end of the survey with the fifty-two (52) patients. On the other hand, the frequency of finger hippocratism went from $3.85 \%$ to $11.54 \%$. This observation could show the clinical improvement for some children but also the evolution towards pulmonary arterial hypertension for others, causing thus the persistence of chronic hypoxia and reducing the intensity of dyspnea. We noticed the appearance of thoracic deformation with four (4) children who were suffering from chronic respiratory distress. In fact, when subjected to intensive efforts and/or permanent respiratory movements, the thorax ends up by adopting a vicious shape. Congenital heart diseases are often associated with other types of malformations. 
Atrioventricular canal is a common heart disease in trisomy of chromosome 21 [20]. In fact, Chéhab and his collaborators [21] in Lebanon observed out of 120 cases of atrioventricular canal $57.5 \%$ of persons with Down's syndrome. We objectivized a lower number. Out of fifteen (15) cases $40 \%$ was subject to Down's syndrome, which is a sign of Trisomy. In Senegal, Fall [22] found that in $46.4 \%$ of the cases, atrioventricular canal was associated with Down's syndromeTrisonomy. In addition to the syndrome of Down which was found in ten (10) patients, we observed other malformations which can be listed as follows: seven (7) polymalformative Syndrome, two (2) encephaloceles, two (2) cleft lip and palate, two siamese twins, one case of microphtalmia, an inequality in terms of length of the inferior limbs and an hydrocephalus). Other authors showed the link between these malformative associations but at different degrees. In Burkina-Faso, Soubeiga [23] recorded six (6) cases of polymalformative syndrome, two (2) cases of Down's syndrome, one case of creft lip and palate and Sawadogo [7] noticed one case of emphaloceles. Daou [24] in Mali recorded thirteen (13) cases of trisomy, eight (8) cases of polymalformative syndrome, Seven (7) cases of emphaloceles out of a total of fifty-one (51) congenital heart diseases.

In these situations, the etiologies of congenital heart diseases are probably due to genetic anomalies namely chromosomal aberrations. Trisomy of chromosome 21 is one of the chromosomal aberrations the most common because it is the most viable form. The pleiotropic action of genes could explain the frequency of malformative associations. As a matter of fact, the highlighting of one or several visible congenital heart diseases of a child must always be subjected to a research of other anomalies mainly visceral. At the moment of the diagnosis, out of the 101 patients, only 36 were able to do an electrocardiogram which highlights 21 cases of anomalies with $8.91 \%$ of right ventricular hypertrophy. At the last check-up, sixteen (16) patients out of fifty-two (52), had benefited from an electrocardiogram that was pathological in two cases (a bi-ventricular hypertrophy and a left-ventricular hypertrophy representing each a percentage of $1.92 \%$ ).

The front chest $\mathrm{x}$-ray carried out only on thirty-three (33) children revealed a cardiomegaly in $12.87 \%$ of the cases at the moment of the diagnosis. Out of the fifty-two (52) patients consulted again in 2014, this test was carried out on twenty (20) cases and $9.62 \%$ of the patients were suffering from a cardiomegaly. Kinda [14] in Senegal, found thanks to the electrocardiogram, that $64.89 \%$ of his patients were suffering from a right ventricular hypertrophy and the same percentage had a cardiomegaly. As for Damarou and his collaborators [17] in Togo they found a percentage of $89 \%$ of cardiomegaly. Our low data could be explained by the non-realisation of these tests by the majority of the patients at the moment of the diagnosis as well as during the follow-up because of the low socio-economic standards of the patients. This made the appreciation of the electrocardiographic and radiographic evolution of the different anomalies difficult. In the management of congenital heart diseases, the medical treatment is most often prescribed while waiting for a surgical treatment.

During the follow-up as well as at the moment of the diagnosis, the majority of the patients were under drug therapy with respectively $63.37 \%$ and $51.92 \%$. The most pre- 
scribed drugs in 2012 were Furosemide (22 cases representing 42.31\%) and potassium (20 cases representing 38.46\%) and respectively 21 cases (40.38\%) and 20 cases (38.46\%) in 2014. Kinda [14] in his survey found that $54.26 \%$ of his patients were under diuretic of furosemide type treatment with potassium supplements. In Tunisia, Hammami and his collaborators [13] found that $46.3 \%$ of the cases were under drug therapy.

However, some patients whose clinical aspect did not require any drug therapy did not receive any. Yet, a regular monthly or quarterly check-up was always necessary for all the patients. The surgical treatment remains the curative treatment for congenital heart diseases. In our case it was recommended for $63.37 \%$ of the patients (64 cases) in 2012 and only $7.81 \%$ (5 cases) had undergone a surgery. This number is close to Kinda's in Senegal [14] who recorded 6 patients (6.82\%) who underwent surgery out of 94 (93.62\%) for whom surgery was required. Other authors in developing countries found that only 11 to $26 \%$ of the operations were carried out [12] [25] [26]. Throughout the follow-up, we noticed $42.31 \%$ (22 cases) of congenital heart diseases which necessitated surgery compared to $57.69 \%$ (30) cases at the moment of the diagnosis of the fifty-two (52) children. In fact, out of the thirty (30) patients, fifteen (15) recovered, three (3) no longer needed surgery and we set ten (10) new indications; None of the twenty-two (22) cases which required surgery in 2012 recovered spontaneously. The number of patients who benefited from heart surgery in developing countries still remain low compared to the one of developed countries where more than $80 \%$ of the cases requiring surgery underwent it [27]. Given the impossibility of access to surgical cure at the local level due to the lack of technical facilities, transferring patients abroad remains the only rescue for cases necessitating surgery. In fact, the low number of operations performed could be justified by the high cost of medical transfer in the sub-region compared to the low revenue of the population. After the different surgeries, we noticed three (3) cases of recovery and two (2) cases with steady clinical status. The post operation evolution of these two (2) children was characterized by aortic insufficiency in a case of aorta stacked stenosis and a mitral regurgitation in an association of interventricular septal defect + atrioventricular canal and a large mitral valve prolapse. Contrary to M'pemba and his collaborators [10] in Congo with 98\%, Kinda [14] and us (60\%), Goeh and his collaborators [28] had $100 \%$ of curative surgical treatment in their series. Despite its importance in the management of heart diseases, surgery does not always permit a complete recovery but almost always improves the cardio-vascular function and remains the best treatment to the extent of its indication. Among the fifty-nine (59) children who were not operated upon, thirty (30) were alive (28 with a steady status and 2 with an unsteady one); twenty-one (21) died and represented $35.59 \%$ of the non-operated cases and the others were no longer met. Nevertheless, this high mortality rate was inferior to Chaabouni and his collaborators' in Tunisia [8] who registered an important mortality rate of 59.5\% among the non-operated patients. Our mortality rate could be under-estimated because of the important number of patients who have disappeared.

These deaths highlight the importance of surgery in the management of malforma- 
tive heart diseases and the necessity of creating an operating center for cardiovascular surgery which is accessible to populations in all developing countries. An analysis of the fifty-two (52) cases of children kept under observation till the end of the survey in 2014 revealed that only one (1) patient had an unsteady clinical status in 2012 whereas the other fifty-one (51) who represented $98.08 \%$ had a steady status. Yet, in 2014, it was possible to realize the filling of this child's intraventricular septal defect thanks to Doppler echography. A spontaneous recovery was noticed with eleven (11) other children and a recovery after surgery was with three (3) children. We noticed that more than half of the cases of isolated atrial septal defect (57.14\%) were progressing spontaneously towards recovery. This result corroborates Fischer and his collaborators' in Austria [29] who registered a percentage of $56 \%$ of spontaneous filling in cases of atrial septal defect. The clinical status was steady in 34 cases $(65.38 \%)$ and unsteady in 3 . The evolution of congenital heart diseases without surgical treatment is almost always associated with complications. Eisenmenger's syndrome was the most common complication among the 101 patients where six cases representing 5.94\% were discovered. In Senegal, Kinda [14] registered a higher number of Eisenmenger's syndrome: ten cases among his patients (22.73\%). After him comes Previte [30] and his collaborators in the USA who reported $11 \%$ of the cases. This syndrome complicates the spontaneous evolution of heart diseases with "a left-right shunt" which is responsible of an important and prolonged blood flow in the lung blood. We discovered two (2) cases of infectious endocarditis representing $1.98 \%$; this number was inferior to Lefebvre and his collaborators' [31] who reported 5\% of the cases of infectious endocardidis in France. This difference could be explained by the type of our study which is transversal. A case of encephalopyosis was discovered on a thirteen years old child who was suffering from fallot's disease". Its evolution was fatal after his transfer to the service of Neurology for better care. Ould and his collaborators [32] in their survey in Senegal noted the scarcity of this complication but also the heavy toll which is associated with it. Out of ninety-four (94) cases of congenital heart diseases, Kinda [14] discovered two cases of encephalopyosis (on fallot's disease and fallot's disease + persistence of the arterial channel) who all died. A case of auricle arythmia (Chronic atrial fibrillation) was discovered on a aortica stacked stenosis with a steady clinical status. In our series, we noticed that the associations "atrioventricular canal + atrial septal defect" and the "communication left ventricle - right auricle" were the deadliest with a percentage of $100 \%$ followed by atrioventricular canals( 67\%), Fallot's disease (67\%) and the associations of "Fallot's disease + Atrial Septal Defect" (67\%). Yet, apart from the only case of "communication left ventricle - right auricle" who died the deadliest nosologic forms were the atrioventricular canal (75\%) and Fallot's disease (67\%). We registered fifteen (15) cases of death in 2012, eleven (11) cases in 2013 and one (1) case in 2014. In total, the percentage of death registered was $26.73 \%$.This rate was superior to Cissé's [1] in Burkina-faso and Brousse and his collaborators' [33] in Senegal who registered respectively percentages of 5.4\% and $18.8 \%$. However, Hammami [13] in Morocco recorded a rate close to ours (23.8\%) whereas Khalil and his collaborators in India [34] recorded a highest rate of 
34.9\%.This large interval of death could be justified by the period of the survey. In African countries, deaths are mainly due to the lateness of the diagnosis and the difficult access to appropriate health care. The lack of financial means as well as the distance separating the patients 'houses and the hospital where treatments were done could explain why many patients stop going to the hospital in our context $(21.78 \%$ representing 22 cases). Out of the fifty-two (52) patients, the prognostic was estimated good for forty (40) of them. The atrioventricular canal and complex congenital heart diseases (interventricular septal defect, transposition of the great arteries, single auricle, single ventricle," mitral atresia", double outlet right ventricle) had the worst prognostics

\section{Conclusion}

Congenital heart diseases are relatively common at CDG-PTH. The sixteen months' follow-up of 101 cases diagnosed in 2012 allowed us to notice that they generally had bad diagnosis with 27 cases of death (representing 27\%), 22 cases we were no longer in touch with and only fifty-two (52) children were seen again. The tolerance at the clinical level was bad in $5.77 \%$ of the cases where we had iterative appearance of complications and decompensation. The high rate of mortality noticed is due to an unmet health need, namely heart surgery and catheterism intervention, which is not available in our country.

\section{References}

[1] Cissé, H. (2013) Etats des lieux des cardiopathies de l'enfant au Centre Hospitalier Universitaire Pédiatrique Charles De Gaulle. Mémoire DES pédiatrie, Université de Ouagadougou, Ouagadougou, No. 2505, 81 p.

[2] Iselin, M. (1999) Cardiopathies congénitales. Encyclopédie Médico-Chirurgicale (Elsevier Paris), Radiodiagnostic-Cœur-Poumon, 32-015-A-12. Pédiatrie, 4-070-A-05, 6 p.

[3] Chadha, S.L., Singh, N. and Shukla, D.K. (2001) Epidemiological Study of Congenital Heart Disease. The Indian Journal of Pediatrics, 68, 507-510. http://dx.doi.org/10.1007/BF02723241

[4] Himmetoglu, O., Tiras, M.B., Gursoy, R., Karabacak, O., Sahin, I. and Onan, A. (1996) The Incidence of Congenital Malformations in a Turkish Population. International Journal of Gynecology \& Obstetrics, 55, 117-121. http://dx.doi.org/10.1016/s0020-7292(96)02743-9

[5] Bassili, A., Mokhtar, S.A., Dabous, N.I., Zaher, S.R., Mokhtar, M.M. and Zaki, A. (2000) Congenital Heart Disease among School Children in Alexandria, Egypt: An Overview on Prevalence and Relatives Frequencies. Journal of Tropical Pediatrics, 46, 357-362. http://dx.doi.org/10.1093/tropej/46.6.357

[6] Ouafae, A. (2010) Profil épidémiologique et étiologique des cardiopathies congénitales : à propos de 427 cas colligées dans le service de pédiatrie CHU Hassan 11 Fès. Thèse Méd, Université Sidi Mohamed Ben Abdellah, Fes, No. 62, 191 p.

[7] Sawadogo, P.G.E. (2007) Cardiopathies congénitales de l'enfant : aspects épidémiologies, diagnostiques, thérapeutiques et évolutifs dans le service de pédiatrie du Centre Hospitalier universitaire Yalgado Ouédraogo. Thèse Med, UFR/SDS, Université de Ouagadougou, Ouagadougou, No. 10, 147 p.

[8] Chaabouni, M., Kamoun, T., Meki, N., Mahfoudh, A., Karray, A., Daoud, M., et al. (1999) 
Aspects épidémiologiques et évolutifs des cardiopathies congénitales dans le service de pédiatrie de Sfax à propos de 123 cas. Tunisie Médicale, 7, 264-271.

[9] Abdullah, A. (2001) Congenital Heart Disease in 740 Subjects: Epidemiological Aspects. Annals of Tropical Paediatrics, 21, 111-118. http://dx.doi.org/10.1080/02724930120058160

[10] M'pemba, Ab.L., Johnson, E.A. and N'zingoula, S. (2005) Les cardiopathies congénitales observées dans le service de pédiatrie "Grands enfants" du CHU de Brazzaville, à propos de 73 cas: Aspects épidémiologiques. Médecine d Afrique noire, No. 5203, 173-177.

[11] Lahlou, I. (2001) Profil épidémiologique des cardiopathies congénitales au Maroc. Thèse Méd, Université Rabat, 158.

[12] Diop, A.K. (2007) Cardiopathies congénitales à Dakar : à propos de 72 cas recueillis dans le service de pédiatrie de l'hôpital principal de Dakar. ThèseMéd, Université Cheikh Anta Diop Dakar, Dakar, No. 89, 141 p.

[13] Hammami, O., Khadija, B.S., Boujemaa, Z., Chebbi, Y., Aoun, S., Meddeb, I., et al. (2007) Profil épidémiologique et clinique des cardiopathies congénitales chez l'enfant à l'hôpital de Bizerte. Tunisie Médicale, 85, 829-833.

[14] Kinda, G. (2008) Cardiopathies congénitales: aspects épidémio-cliniques, évolutifs et thérapeutiques dans le service de cardiologie du CHU Aristide Le DANTEC de Dakar (à propos de 94 cas). Mémoire CES de cardiologie, Université Cheikh AntaDiop de Dakar, Dakar, No. 143, 155 p.

[15] Talboussouma, S.M. (2013) Cardiopathies congénitales :aspects épidémiologiques et échocardiographiques à propos de 109 cas au centre hospitalier universitaire pédiatrique Charles de Gaulle de Ouagadougou. Thèse Méd UFR/SDS, Université de Ouagadougou, Ouagadougou, No. 171, 100 p.

[16] Kokou, O., Agbèrè, A., Balaka, B., Atakouma, Y., Goeh-Akué, E., Soussou, B., et al. (1999) Apport de l'échocardiographie-Doppler dans le diagnostic des cardiopathies congénitales dans le service de pédiatrie du CHU-Tokoin, à Lomé. Médecine d Afrique Noire, 6, 161164.

[17] Damarou, F., Matey, K., Douti, N., Djato, A., Soussou, B. and Kessié, K. (2010) Les cardiopathies congénitales au Togo. Aspectsépidémiologiques, cliniques, diagnostiques et thérapeutiques: A propos de 141 cas colligés à "Terre des hommes". J. Rech. Sci. Univ. Bénin (Togo), 12, 57102.

[18] Dadez, E. and Cormier, B. (1996) Echocardiographie Doppler: Principes Physiques, Examen Normal. Encyclopédie Médico-Chirurgicale, 11, 10-14.

[19] Nadia, M., Salma, S., Shazia, M. and Heman, D. (2014) Spectrum of Heart Disease in Children under 5 Years of Age at Liaquat University Hospital Hyderabad Pakistan. Indian Heart Journal, 66, 145-149. http://dx.doi.org/10.1016/j.ihj.2013.12.041

[20] Heitz, F. (2008) Cardiopathies congénitales. Encyclopédie Pratique de Médecine. Masson, Paris, Traité De Pédiatrie, $14 \mathrm{p}$.

[21] Chehab, G., El-Rassi, I., Abdo, A., Fakhoury, H., Chokor, I., Haddad, W., et al. (2010) Atrioventricular Septal Defect Characteristics in Infants with and without Down's Syndrome: A Lebanese Study. Le Journal Medical Libanais, 58, 3-7.

[22] Fall, A.L. (2000) Le canal atrio-ventriculaire: Aspects épidémiologiques, anatomo-cliniques et évolutifs à propos de 28 cas au CHU de Dakar. Thèse Med, Université Cheikh Anta Diop de Dakar, Dakar, Vol. 88, 100 p.

[23] Soubeiga, E. (2008) Détresses respiratoires d'origine cardiaque du nouveau-né: Aspects épidémiologiques, cliniques et para cliniques, dans le service de pédiatrie du CHUYO. A propos de 29 cas. Thèse Méd, UFR/SDS, Université de Ouagadougou, Ouagadougou, Vol. 
$41,142 \mathrm{p}$.

[24] Daou, H. (2008) Etude prospective des cardiopathies congénitales entre 0 et 2 mois au service de réa-pédiatrie de l'hôpital Gabriel Touré d'avril 2005 à septembre 2006 à propos de 51 cas. Thèse Méd, Université de Bamako, Bamako, 65 p.

[25] Bannerman, C.H. and Mahalu, W. (1998) Congenital Heart Disease in Zimbabwean Children. Annals of Tropical Paediatrics, 18, 5-12. http://dx.doi.org/10.1080/02724936.1998.11747918

[26] Diop, I.B., Ndiaye, M., Ba, S.A., Sarr, M., Kane, A., Sow, D., et al. (1996) La chirurgie des cardiopathies congénitales au Sénégal. Indicationsopératoires, bilan et Perspectives. Dakar Medical, 41, 85-90.

[27] Tefuaruni, N., Hawker, R., Vince, J., Sleigh, A. and Williams, G. (2001) Congenital Heart Disease in Papua New Guinean Children. Annals of Tropical Paediatrics, 21, 285-292. http://dx.doi.org/10.1080/07430170120093463

[28] Goeh, A.E., Kenou, A., Ekoue-Kouvahey, D. and Soussou, B.L. (2013) Health Transfer of Togolese Children for Cardiac Surgery by NGO “Terre des Hommes" about 60 Cases from 1993 to 2003. Cardiologie Tropicale, 130, 1-10.

[29] Fischer, Y., Sonnweber, N., Sailer, M., Fink, C., Trawoger, R. and Hammerer, I. (1991) Incidence of Congenital Heart Disease in Tyrol, Austria 1979-1983. Pädiatrie \& Pädologie, 26, 57-60.

[30] Previte, J. and Haran, P. (2001) Syndrome d'Eisenmenger. Journal of Cardiothoracic and Vascular Anesthesia, 5, 167-178.

[31] Lefèvre, M. and Guérin, P. (2004) Endocardites de l'enfant et du petit enfant. EMC-Cardiologie-Angéiologie, 1, 242-255. http://dx.doi.org/10.1016/j.emcaa.2004.03.004

[32] Ould Ahmedou Salem, M.S. (2006) Abcès cérébraux compliquant les cardiopathies congénitales cyanogènes: à propos de cinq (05) cas. Thèse Méd, Université Cheikh Anta Diop de Dakar, Dakar, Vol. 74, 107 p.

[33] Brousse, V., Imbert, P., Mbaye, P., Kieffer, F., Thiam, M., Ka, A.S., et al. (2003) Evaluation au Sénégal du devenir des enfants transférés pour chirurgie cardiaque. Médecine Tropicale, 63, 506-512.

[34] Khalil, A., Aggarwal, R., Thirupuram, S. and Arora, R. (1994) Incidence of Congenital Heart Disease among Hospital Live Births in India. Indian Pediatrics, 31, 519-527. 
Submit or recommend next manuscript to OALib Journal and we will provide best service for you:

- Publication frequency: Monthly

- 9 subject areas of science, technology and medicine

- Fair and rigorous peer-review system

- Fast publication process

- Article promotion in various social networking sites (LinkedIn, Facebook, Twitter, etc.)

- Maximum dissemination of your research work

Submit Your Paper Online: Click Here to Submit

Or Contact service@oalib.com 